\title{
STRATEGY IMPLEMENTATION PROBLEMS IN SMALL AND LARGE COMPANIES - SIMILARITIES AND DIFFERENCES IN LIGHT OF THE RESEARCH RESULTS. LESSONS FROM THE POLISH EXPERIENCE
}

The literature on the strategic management emphasizes the essence and importance of both the good formulation and the proper implementation of the strategy. However, business practice shows that while companies have quite highly developed skills in the area of strategy formulation, at the same time they are characterized by a surprisingly low level of skills in the scope of the effective implementation of the strategy. Various factors that affect the effectiveness of the implementation process are mentioned, including poorly developed leadership skills among management staff, the improper allocation of decision-making powers, the incompetent communication of the strategy, the lack of ability to manage changes, and the lack of appropriate motivators associated with the strategy being implemented. It is worth considering whether the companies that achieve market success are also facing such problems in the strategy implementation process. This paper is based on the results of the research conducted as part of the project entitled "The implementation of the

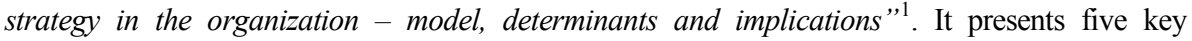
problems faced in the strategy implementation process by small and large companies that can be considered to be effective in implementing their development concepts. It appears that the implementation of the strategy in such companies is usually hindered by two problems: "management staff overloaded with current problems" and "attention of employees focused on operational activities". Most problems are associated with the changes occurring in the environment and the lack of appropriate motivators.

Keywords: strategy, strategy implementation, implementation problems, small and large companies

DOI: $10.15611 /$ aoe.2018.2.17

\section{INTRODUCTION}

In today's turbulent environment, in which the determinants of global development are changing very rapidly, the achievement of measurable benefits by companies requires not only the ability to formulate valuable

\footnotetext{
* Department of Strategic Management, Wrocław University of Economics.

${ }^{1}$ The project was financed from funds of the National Science Centre allocated based on the decision No. DEC-2011/03/B/HS4/04247.
} 
strategies but first of all the ability to implement them effectively. The research results published indicate that the competent implementation of the strategy becomes a critical factor determining the development's success. These results show the alarming incapacity of companies when it comes to the effective implementation of the strategies developed. Various sources say that the strategy implementation process ends in failure for $50-90 \%$ of companies ${ }^{2}$. In view of the above, the following question arises: what type of problems cause that companies fail to implement the strategies adopted? When analyzing the literature of the subject, many factors that contribute to the failure of the strategy implementation process can be found. Among such factors the following are commonly mentioned: poorly developed leadership skills among management staff, the improper allocation of decision-making powers, the incompetent communication of the strategy, the lack of ability to manage change, and the lack of appropriate motivators associated with the strategy being implemented. One can ponder whether companies that achieve market success are also affected by the aforementioned problems in the strategy implementation process and whether there are any differences in the sets of problems that affect small and large companies. To answer this question it is necessary to examine the entities that successfully implement the strategies adopted. Such procedures were conducted as a part of the project entitled "The implementation of the strategy in the organization - model, determinants and implications", whereas this paper presents five key problems that have been faced in the strategy implementation process by small and large companies that can be considered to be effective in implementing their development concepts.

\section{PROBLEMS ENCOUNTERED DURING THE IMPLEMENTATION OF THE STRATEGY IN COMPANIES - A REVIEW OF THE LITERATURE OF THE SUBJECT}

The literature of the subject emphasizes the essence and importance of both the good formulation and the proper implementation of the strategy. However, while much space and attention were given to the problems associated with strategy development, the issues of skillful strategy implementation still remain relatively poorly recognized. An analysis performed by Hutzschenreuter and Kleindienst (2006) provides interesting

\footnotetext{
${ }^{2}$ Kaplan and Norton (2005a), Gendron (1997), Balanced Scorecard Statistics (accessed on 20/05/2015); Carlopio and Harvey (2012), Speculand (2006), Miller (1997).
} 
information in this regard. It indicates that out of the 991 analyzed papers related to the strategy, only 66 concerned the issues associated with strategy implementation. However, it should be noted that in recent years problems of the strategy implementation have become an interesting area to explore. This is important insofar as the strategy implementation process, according to Abraham and Leavy (2007) and Wołczek (2012), is considered to be the most critical stage of the strategic management procedure.

The strategy implementation process is affected to a considerable extent by the quality of the stage of the strategy development and the people involved in it. One could agree with the statement formulated by Abraham (2006) that the initiation of the work on the strategy and the responsibility for its course is among the tasks of the company's management and owners. However, the work on the strategy itself should involve a wider group of participants, because it is important to utilize the knowledge, skills and experience of other members of the company, especially of those who will perform key roles in the strategy implementation process.

In turn, the stage of strategy implementation requires the involvement of all employees. The level of such involvement will depend on the employees' knowledge about the strategy and on linking the incentive system with the effects of the strategy implementation. Furthermore, it seems that a key role in the strategy implementation process is to be played by mid-level managers who must skillfully translate the top management's expectations concerning the strategy into daily workload of their subordinates, who in turn constitute an essential element in the process of realizing the strategic goals of the company. On top of all that there is also the issue of providing the company with appropriate methods and tools that will allow translating the strategy into operational activities, as well as monitoring and measuring the level of completion of such activities and checking whether the company is on the right course.

For many companies it is quite a challenge to switch from the level of "formulated strategy" to the level of "strategy being implemented" and bring about a situation in which, according to Pugh and Bourgeois III (2011), the strategy "comes to life" and becomes a real action - "the strategy in action" of Abraham and Leavy (2007). Carciumaru and Candea (2012) claim that is because the implementation of the strategy is a difficult process that requires rigorous planning accompanied by proper communication, the appropriate adjustment of the organization and the continuous monitoring of the activities taken. 
Difficulties with translating the strategy into real actions cause the following question to arise in the company: what factors cause us problems in strategy implementation?

The literature of the subject indicates various factors affecting the strategy implementation process ${ }^{3}$. The results of the studies conducted by some authors are given below.

Beer and Eisenstat (2000), after ten years of research conducted in 12 companies, identified "the six silent killers" of strategy:

- top-down or laissez-faire senior management style,

- unclear strategy and conflicting priorities,

- an ineffective senior management team,

- poor vertical communication,

- poor coordination across functions, businesses or borders,

- inadequate down-the-line leadership skills and development.

When analyzing these factors, it can be concluded that most of them relate to the executive staff and their business management skills. According to Beer and Eisenstat (2000), "the silent killers" of strategy implementation exist in most companies, but too many managers avoid confronting them, while only with such an approach it is possible for the organization to learn and consequently succeed in implementing the strategy.

A review of the results of the surveys conducted in 2003 by Hrebiniak (2005) among the managers involved in the strategy formulation and implementation process allows to indicate the following five key factors that hinder the implementation of the strategy:

- inability to manage change effectively or to overcome internal resistance to change,

- trying to execute a strategy that conflicts with the existing power structure,

- poor or inadequate information sharing between individuals or business units responsible for strategy execution,

- unclear communication of responsibility and/or accountability for the execution of decisions or actions,

- poor or vague strategy.

From the list above it appears that the companies in the strategy implementation process face mainly the problems associated with the communication and the lack of appropriate managerial skills. Another problem

\footnotetext{
${ }^{3}$ Salih and Doll (2013) Markiewicz (2013), Čatera and Pučko (2010) Hrebiniak (2005), Three Reasons Why Good Strategies Fail: Execution, Execution... (accessed on - 22/05/2015), Saunders, Mann and Smith (2008), Beer and Eisenstat (2000), Al-Ghamdi (2005).
} 
is the poor quality of the strategy, which suggests that mistakes were already made at the stage of strategy formulation. In addition there are conflicts between the company's power structure and its strategic objectives.

Neilson, Martin and Powers (2008), based on their experience in working with over 250 companies on a more effective implementation of the strategy, identified four key areas affecting the strategy implementation process: decision-making powers, flow of information, motivators, organizational structure. Then they created a list of 17 traits of an organization - each of them corresponding to one or more areas, and conducted surveys for five years, which allowed them to collect data from over 26,000 respondents from 31 companies. Based on this information the traits with the greatest impact on the company's effectiveness in the strategy implementation process were determined. The first five traits are presented in Table 1.

As can be seen, the top five traits of an organization that have the greatest impact on the effectiveness of the strategy implementation process (strength index) include three in the area of "information" and two in the area of "decision-making powers". These traits occur in most companies considered to be strong in the strategy implementation, which indicates that they have a positive impact on the effectiveness of the strategy implementation process. When analyzing the responses of companies considered to be weak in strategy implementation, it should be stated that their weakness results from underestimating the importance of the proper allocation of decision-making powers and the role of the information flow from the environment to the organization and the information flow within the organization.

Al-Ghamdi (2005) in the paper "Obstacles to Successful Implementation of Strategic Decisions: The Saudi Case", based on surveys carried out among 125 Saudi companies, presents a list of seven key issues hindering strategy implementation:

- training and instruction given to lower level employees were inadequate (39.4\% of responses),

- people are not measured or rewarded for executing the plan $(36.2 \%)$,

- the implementation took more time than originally allocated (35.6\%),

- changes in responsibilities of key employees were not clearly defined $(33.3 \%)$,

- competing activities distracted attention from implementing this decision $(33.1 \%)$,

- deviation from the original plan's objective (31.6\%),

- lack of understanding of the role of organizational structure and design in the execution process $(30.3 \%)$. 
This time the analysis of the list above allows concluding that the key issues hindering strategy implementation may include: inadequate preparation of the lower-level employees for the implementation of the strategy, lack of connection between the remuneration system and the strategy being implemented, a wrongly estimated time needed to implement the development concept, unclear definition of responsibilities of key employees for the success of the strategy implementation process, as well as focusing the attention on the current competing activities.

The last section of the presented information concerning the problems in the strategy implementation comes from the study of Čater and Pučko (2010), who presented the results of the surveys conducted in 2008 among 172 micro, small, medium and large Slovenian companies. The authors created a list of the thirteen most common obstacles hindering the implementation of strategy, which they classified into five different groups: "problems in strategy formulation" (two obstacles), "change management problems" (one obstacle), "organizational culture problems" (three obstacles), "problems related to organizational power structure" (three obstacles), and "leadership problems" (four obstacles). An analysis of the research results leads to the conclusion that the main obstacles hindering effective strategy implementation among Slovenian companies include those classified by the authors into the following areas:

- "leadership":

- reward systems that do not stimulate to action, weakness in communicating the strategy to lower levels of the organization,

- managers lack leadership skills for strategy implementation,

- "organizational power structure":

- managers lack ideas of how to persuade employees to execute the strategy,

- top management is not actively engaged in strategy implementation,

- "strategy formulation":

- strategy is poorly defined.

When analyzing the above results of the research concerning the factors hindering strategy implementation, it can be concluded that the key problems (apart from the time and financial aspects) are associated with the attitudes and skills of the management staff (the management style used, building employee engagement, change management skills, the role of the management staff), functioning of the communication and information flow system (communication of the strategy, providing the information to the key 
persons in the strategy implementation process, providing the information about the progress in the strategy execution, knowledge sharing), as well as with the design of the incentive system (factors encouraging involvement in the strategy implementation process, linking the rewards with the level of completion of strategic objectives).

It seems therefore that the company that wants to increase its chances for the successful implementation of the strategy should make the management staff adopt a proper management style which will promote the involvement of the employees implementing the strategy. The studies carried out by Salih and Doll (2013) show that a participative management style promotes the involvement of employees and thus affects the strategy implementation process. In addition it is important to skillfully manage the changes, in particular to properly translate the strategic objectives into operational activities and adjust the employee activities to them. It may be also helpful in this regard to design organizational processes and activities as well as to define the necessary employee skills that will enable the smooth transition from the level of "formulated strategy" to the level of "strategy being implemented". Another important element in the strategy implementation process is the level of knowledge among the employees about the company's strategy. According to Cocks (2010), an organization that does not inform all its employees about the strategic plans exposes itself to the risk of misinterpretation of the actions taken, which may result in the failure of the strategy implementation process. Understanding the strategy by the participants in the organization requires effective and continuous communication. Unfortunately, it turns out that on average up to $95 \%$ of employees do not know or do not understand the company's strategy according to Kaplan and Norton (2005b), Jones (2010) and Balanced Scorecard Statistics (accessed on - 20/05/2015). The success of the strategy implementation process also depends on how much time the company managers spend on discussing the strategy. The studies conducted by Kaplan and Norton - see Kaplan (2009) - reveal that $85 \%$ of senior management spend less than one hour a month discussing strategy. What is worse, $50 \%$ of the respondents did not spend even one hour a month discussing the strategy. If the company's management spends so little time on this, the pace of its implementation and the problems encountered, it is no wonder that the strategy implementation process so often fails. It seems that training could be a solution that would contribute to a greater focus on strategy by the management staff and other employees. Some researchers, Hussey (1985), 
Tovey (1991), Mason (1993), indicate that training in the scope of management as well as employee development programs can be used to achieve the objectives of the organization. The problems associated with strategy implementation as the key subject of training programs may bring measurable benefits in the strategy implementation process. Alexander (1985) mentions the role of the proper preparation of the employees for the implementation of strategy. When examining the problems faced by US companies during the implementation of their strategy, he found that about two-thirds of the surveyed companies indicated that the skills of the employees were inadequate to the new tasks associated with the strategy implementation. Therefore, training can help the employees understand the company's strategy and contribute to the creation of the attitude of involvement in the strategy implementation. In addition, training can be used to prepare many detailed tasks that must be taken to transform the strategy into real actions. Hussey (1996) states that adequate training initiatives can bring understanding and commitment to the strategy implementation as well as provide the organization with appropriate employee skills so that the implementation of the strategy is possible. What is more, the training can significantly contribute to improving the skills of the managers involved in the strategy implementation process. According to Isherwood (2011), this is important insofar as the research results show that managers with the appropriate qualifications are more inclined to use strategic tools, which then may help in the strategy implementation process. Finally, it should be noted that in the strategy implementation process it is also important to build such an incentive system that will link the rewards of employees with the effects of the strategy; it appears in practice that companies are unable to properly build an incentive system which would encourage employees to become involved in the implementation of the strategy, while the remuneration of the management staff is not associated with the effects of the execution of the company's strategy. According to Kaplan and Norton (2005b), the studies show that, on average, $70 \%$ of mid-level managers and over $90 \%$ of line employees in organizations are rewarded regardless of whether the implementation process succeeded or failed. Yet it seems that building an incentive system that links the remuneration of employees with the effects of the strategy is essential for achieving the strategic objectives. 


\section{PROBLEMS ENCOUNTERED DURING THE IMPLEMENTATION OF THE STRATEGY IN SMALL AND LARGE COMPANIES - RESEARCH RESULTS}

\subsection{Research methodology}

When designing the survey, the authors looked for companies that could be considered to be effective in the implementation of their strategies. As a result of the analyses, the authors decided to select for the research sample those companies that have been operating for at least five years and are included in the list of the 500 largest Polish companies according to the ranking of the "Polityka" weekly or in the "Diamenty Forbesa 2013" (Forbes Diamonds 2013) ranking. When deciding on the selection of such a research sample, the authors were guided by the belief that the presence of a company in either of those rankings was proof of the effective implementation of the strategic objectives. Therefore a company can be included in the list of the "Polityka" weekly only if apart from a sufficiently high level of revenues from sales it can demonstrate appropriate levels of total revenues, gross and net profit, and employment. In order to be included in the "Diamenty Forbesa" ranking, a company must be classified among the group of the entities with the fastest rate of increase in their value. Considering the above, it is necessary to take into account the structural differences between those two rankings - they present decidely different companies. In the ranking of "Polityka" large companies predominate, while the "Diamenty Forbesa" ranking includes mainly small businesses.

In order to ensure the highest possible representativeness of the surveys, the research sample was selected using the stratified random sampling method, which guarantees that all the important groups of respondents will be reached as each stratum is represented. Within each part, research units (individual companies that meet specific criteria for the individual strata) are selected at random in proportion to their actual participation in the general population. Thus, the structure of the research sample accurately reflects the structure of the general population. Research units within individual subgroups are selected using the simple random sampling method, which means that each unit in a given stratum has the same probability of being included in the sample.

Proportional stratified random sampling was used in the survey. This consists in selecting from each stratum such a number of elements that is proportional to the number (share) of a given stratum in the general 
population. This sampling technique highly facilitates the data analysis by providing the possibility to perform calculations for the entire sample at the same time and not for each stratum separately.

The main variable in the selection of entities for the research sample was the location according to province. The size of the main research sample was set at the level of 200 companies (the size of the general population was assumed as $\mathrm{N}=500$ ). Based on the calculations performed for the significance level $\alpha=0.05$, the value of the maximum standard error of proportion for the main part of the survey was determined at the level of approximately 5.4\%, which is a low value in social research.

Finally, 200 representatives of the companies took part in the survey - 101 representatives of the companies included in the "500 Polityki" ranking and 99 representatives of the "Diamenty Forbesa" ranking.

The research technique used in the study was Paper and Pencil Interview [PAPI]. The questionnaire contained 46 questions in the main part and 12 questions in the demographic part.

\subsection{Characteristics of the population surveyed}

The group of 200 companies included 68 small businesses $(34.0 \%$ of the total number), 65 medium companies (32.5\% of the total number) and 67 large enterprises (33.5\% of the total number). For the purposes of this paper, small and large companies were taken from the study population in order to be analyzed.

From among the 68 small companies, as many as 64 (94.1\%) were included in the "Diamenty Forbesa" ranking. The remaining 4 companies (5.9\%) were from the "Polityka" ranking, whilst out of 67 large enterprises, $64(95.5 \%)$ represented the "Polityka" ranking, while the remaining $3(4.5 \%)$ were from the "Diamenty Forbesa" ranking.

When analyzing the study population in terms of the company's ownership structure, it should be noted that all the entities from the group of small companies were wholly privately owned. In the group of large companies, $67.2 \%$ of the entities were wholly privately owned. Another $25.4 \%$ of them are companies with a majority stake (over 50\%) owned by public entities (e.g. the State Treasury), while $7.5 \%$ are companies with a minority stake (less than 50\%) owned by public entities (e.g. the State Treasury). It can therefore be concluded that public capital is involved in every third large company. Such a situation should not be surprising, because privately-owned companies practically had not existed before 1989 
in Poland - where the state-held structure of ownership predominated. After 1989, the change of the political system occurred (the transition from socialism to captalism) and of the economic system (the transition from a centrally planned economy to market economy). However the state still owned the companies operating at that time, out of which the vast majority were medium and large enterprises. In order to cope with the global competition, successive governments in Poland continued the process of privatization of state-owned companies, leading to the currently small number of wholly state-owned companies. However public entities such as the State Treasury have majority or minority stakes in many formerly stateowned companies. It is therefore not surprising that in the group of large companies, public capital is involved in every third entity.

Another variable describing the companies surveyed is the financial result achieved at the end of 2012. The analysis of the data shows that the vast majority of both small $(89.7 \%)$ and large $(85.1 \%)$ entities had a positive financial result for 2012. These data can therefore be regarded as a sign of the positive trends in the financial standing of the companies surveyed and, indirectly, also as an indicator of the effectiveness of the strategy implementation.

The next question concerned the form of the strategy functioning in the companies surveyed. The results obtained are presented in the figures below (Figures 1 and 2).

It turned out that almost seven of ten small businesses had nonformalized strategies, nearly $30 \%$ of such entities based on a strategy that existed only in the mind of the boss, every fifth company was functioning based on verbal arrangements known only to senior management, whilst in almost every fifth company the arrangements concerning the strategy were known to every employee. Only slightly more than $30 \%$ of the small businesses had formalized strategies.

To compare, in the group of large companies only one entity (which accounted for $1.5 \%$ of those who responded) had a strategy that existed only in the mind of the boss. Every fourth large company functioned on the basis of a strategy in the form of verbal arrangements known only to the senior management, while in nearly $30 \%$ of such entities the verbal arrangements concerning the strategy were known to every employee. In addition, almost $45 \%$ of the companies surveyed had a formalized strategy. It should also be noted that almost every third large company had a formalized strategy in the form of a document known to every employee of the company. Therefore it can be concluded that almost $70 \%$ of small businesses and over $55 \%$ of large 
enterprises have non-formalized strategies.Knowing the forms of the strategies among the entities surveyed, the authors wanted to determine the periods, which the strategies anticipate.

As can be seen in Figure 3, strategies in large enterprises are characterized by a time horizon that looks further ahead - over $40 \%$ of large companies have strategies that look more than 3 years ahead. Only a little more than $19 \%$ of small businesses can boast of the same time horizon of the strategy. If we take into account only two responses: the strategy concerns "up to 3 years" and "more than 3 years" ahead, it turns out that almost $66 \%$ of large companies have three-year or longer strategies (by comparison among small companies such a time horizon of the strategy was followed by slightly more than $38 \%$ of the companies surveyed).

Small businesses strongly rely on short-term strategies - over $38 \%$ of such entities have strategies that look ahead no more than one year, while $22 \%$ of them - no more than two years. By comparison, large companies with a time horizon up to one year accounted for $13.4 \%$ of the respondents. Entities with a time horizon of a strategy no longer than two years constituted the same percentage of the large companies surveyed.

The analysis of the data contained in Figure 3 allows for stating that along with the increase in the time horizon of the strategy, the percentage of small businesses decreases, while the percentage of large companies that have strategies looking further and further ahead increases.

The last variable characterizing the companies surveyed is the frequency of updates to the strategy. The results obtained are presented in Figure 4.

As can be seen in Figure 4, 76.5\% of small companies update their strategies at least once a year, out of which $35.3 \%$ - at least once every six months. By comparison, the percentage of large companies updating their strategies at least once a year amounted to $47.7 \%$, out of which the percentage of the entities revising their strategies at least once every six months was only $16.4 \%$. It should be noted that large companies most often (34.3\% of responses) update their strategies once every 2-3 years.

Therefore, small businesses update their strategy more often than large enterprises. This probably results from the less formal character of strategies in small companies, which enables easier and less problematic change of assumptions.

The small businesses surveyed managed to implement their strategies at an average level of $73 \%$. It should be noted here that 51 out of 68 small businesses, which accounts for $75 \%$ of the study group, declare that they implement their strategies at a level of at least $70 \%$. For these 51 companies 
the average level of the strategy implementation was $81 \%$. The remaining 17 small companies $(25 \%$ of their total number) implement their strategies at a level not higher than $60 \%$, while the average level of the strategy implementation was $48 \%$.

In the group of large companies the average level of successful strategy implementation is $75 \%$. It is worth emphasizing that 54 out of 67 large companies, which accounts for slightly over $80 \%$ of the study group, declare that they implement their strategies at a level of at least $70 \%$. For these 54 companies the average level of strategy implementation was $83 \%$. The remaining 13 large companies (somewhat less than $20 \%$ of their total number) implement their strategies at a level not higher than $60 \%$, while the average level of strategy implementation was $45 \%$.

It should therefore be concluded that the differences in the strategy implementation level between the groups of small and large companies are insignificant. However, large companies gained a slight advantage in this regard - a higher percentage of these companies implement their strategies at a level of at least $70 \%$.

A statistical profile of a small company and a large enterprise participating in the survey are presented as a summary of this part of the study.

It appeared that the group of small companies participating in the survey included mainly entities fully owned by private capital, while the vast majority of them (89.7\%) generated profits from the business activity. In the group of small companies predominate non-formalized strategies $(69.12 \%)$, among which the largest share $(29.41 \%)$ has the strategy "existing only in the mind of the boss". Small businesses are characterized by the short time horizon of their strategies: the strategies in $38.2 \%$ of them do not look more than one year ahead, while in $22.1 \%$ - no more than two years ahead. Small companies update their strategies quite often $-76.5 \%$ of them update strategies at least once a year, out of which $35.3 \%$ - at least once every six months. The small businesses surveyed manage to implement their strategies at the average level of $73 \%$.

The majority (67.2\%) of the large companies surveyed are owned by private capital and generally $(85.1 \%)$ generate profits from the business activity. Most $(55.39 \%)$ of the large companies have non-formalized strategies, however the predominant form $(32.31 \%)$ of the strategy is a strategy formalized in a form of document known to every employee of the company. Large companies are characterized by the long time horizon of their strategies: the strategies in $40.3 \%$ of them look more than three years 
ahead, while in $25.4 \%$ - exactly three years ahead. Large companies most often $(34.3 \%$ of them) update their strategies every $2-3$ years. Somewhat less frequently ( $31.3 \%$ of responses), the strategy is revised once a year. In the group of large companies the average level of successful strategy implementation is $75 \%$.

\subsection{Problems encountered during the implementation of strategy in small and large companies - similarities and differences}

In this section of the paper we will discuss the issues concerning the key problems faced by the small and large companies characterized by the high efficiency in implementing their strategy.

When commencing the studies the authors wondered whether the situations causing problems in the strategy implementation process would differ depending on the size of the company.

The research questions were as follows:

1) What factors most often hinder the implementation of the strategy in small and large companies? (RQ1)

2) What factors cause most difficulties in the implementation of the strategy in small and large companies? (RQ2)

To answer these questions, a list of factors that could adversely affect the strategy implementation process was prepared. An analysis of literature of the subject, in particular an analysis of the results of the studies on the strategy implementation (some of them were presented earlier in this paper), as well as the experience of the research team in this regard allowed creating the list presented in Table 2 .

For the needs of the studies we defined 29 factors that could hinder strategy implementation. These factors were divided into six areas:

1. Strategy content - SC (5 factors) - this area includes the problems that occur already at the strategy designing stage and later have a negative impact on the implementation process. In particular this applies to vaguely formulated assumptions for the strategy, its internal inconsistency and inflexibility, as well as the excessive number of strategic objectives and defining them irrespective of a reliable analysis of the reality.

2. Organizational structure, procedures and guidelines - SPG (3 factors) this area includes problems associated with the organizational structure not matched to the strategy, the lack of guidelines supporting strategy implementation, and the lack of methods of proceeding in situations critical for the strategy's implementation. 
3. Information flow - IF (5 factors). This area includes problems associated with the incompetent communication of the assumptions for the strategy and its objectives, the poor exchange of the information on the progress of the implementation, the lack of knowledge among employees on their contribution to the strategy implementation process, and information overload that slows down the decision-making process.

4. Leadership - L (7 factors). The "leadership" area can be divided into two sub-areas: "management staff" and "leaders of changes". The problems concerning the management staff that can cause difficulties in the strategy implementation process include: the failure to initiate activities supporting the strategy implementation, the lack of experience and knowledge in the scope of strategy implementation, as well as overloading with current affairs which distracts attention from achieving the strategic objectives. When referring to leaders of changes, the problems include the fact that they do not identify themselves with the strategy being implemented, as well as the fact that there are neither the people who could effectively motivate other employees to implement the strategy, nor those who would take responsibility for the success of the strategy implementation process.

5. Employee involvement - EI (5 factors). This area includes the problems associated with the lack of acceptance of the strategy among line employees, the resulting resistance to the changes required for strategy implementation, the failure to provide information or to share the knowledge useful in the strategy implementation process, the involvement in the strategy implementation process decreasing over time, as well as the attention of employees focused on operational activities irrespective of the strategic objectives.

6. Other - O (4 factors) - this area includes the factors which could not be assigned to the aforementioned areas. This group includes insufficient financial resources assigned for strategy implementation, the changing environment, the lack of appropriate motivators supporting strategy implementation, as well as the occurrence of conflicting interest groups inside the organization which hinder strategy implementation.

The 29 factors that may hinder strategy implementation were used to search for answers to the research questions RQ1 and RQ2.

This section presents the results of the studies on the most common issues and the problems that cause most difficulties in the strategy implementation process in small and large companies recognized as effective in achieving their strategic objectives. The answers given by the respondents were 
subjected to an in-depth analysis. Table 3 presents the five most common problems occurring in the strategy implementation process in small companies.

The analysis of the aforesaid data allows stating that for the group of small businesses the list of the most common problems occurring during the implementation process included the problem faced by almost every fifth company ("the resistance of employees to changes associated with the strategy implementation" $-19.1 \%$ of responses) as well as the problem faced by a little more than every third company ("rapidly changing environment that forces frequent modifications of the strategy being implemented" $36.8 \%$ of responses). It can therefore be concluded that the remaining 24 problems occur more rarely in the small companies surveyed - certainly more rarely than in every fifth of them. It should also be noted that the list of the most common problems in small companies included three out of the five problems from the area of Employee Involvement (EI). It can also be concluded that three problems are linked too closely with each other. The implementation of the strategy is hindered because the management of small companies is overloaded with current affairs. This is probably caused by the fact that less attention and efforts are put into the realization of strategic objectives. Such an approach may cause that the remaining employees who are focusing mainly on their daily, operational activities, will perform them irrespective of the strategic objectives. In the long-term perspective, this can give rise to another problem i.e. the enthusiasm and involvement of employees in the strategy implementation process will decrease over time. It also seems that the first problem and the last problem included in the list are interrelated too. The implementation of the strategy in a company is often associated with the introduction of changes that may cause employee resistance. If we add to this the impact of a rapidly changing environment that forces the frequent introduction of modifications to the strategy being implemented, it can be expected that employee resistance to subsequent changes will intensify.

The next finding concerns the categories of problems faced by small companies characterized by a high efficiency in strategy implementation. The list of the five most common problems included three problems from the area marked "employee involvement", one from "leadership" and one from "other". Thus it can be seen that the largest number of problems concern the human factor: maintaining the employee involvement in the strategy implementation process, which is associated with the fact that they should focus not only on the operational activities but, first of all, on achieving the 
strategic objectives. There is also the problem of overloaded management that instead of leading the employees and motivating them for implementing the strategy, must solve current problems which hinders the strategy implementation.

Another finding concerns the fact that representatives of the surveyed small companies indicated "rapidly changing environment that forces frequent modifications of the strategy being implemented" as the most frequently occurring problem. This may prove that today's biggest challenge for small companies is the skillful adaptation to the rapidly changing environment, which is associated with the ability to develop such strategies that on one hand can be frequently modified and on the other hand will subsequently lead the company to the designated strategic objective (provided that this objective will continue to be reasonable and achievable).

Having already the knowledge about the types of problem situations most often faced by small companies, the authors wanted to find out whether the list of those situations corresponded to the list of the situations that caused most trouble in the strategy implementation process. For determining the extent of the problems that can be caused by a given situation in the strategy implementation process, a five-point scale was used, where " 1 " meant "not a problem at all", while " 5 " - "huge problem". Table 4 lists five problems that cause most trouble in the strategy implementation process in small businesses. The list includes the problems indicated by at least $10 \%$ of the companies surveyed.

An analysis of the data included in Tables 3 and 4 allows concluding that only one problem situation that occurred in the small companies surveyed with the highest frequency was also among the situations that generated most trouble in the strategy implementation process. This is "a rapidly changing environment that forces frequent modifications of the strategy being implemented" (mean $=3.00)$.

Another finding concerns the fact that the problem which causes most difficulties in the strategy implementation process was the lack of sufficient financial resources assigned for the implementation of the strategy $($ mean $=$ 3.82 ). This problem affects $16.2 \%$ of the companies surveyed. Therefore, it can be concluded that small companies have difficulties in the accurate estimation of the costs associated with the implementation of the development concept adopted by them.

The third factor that causes most problems with the implementation is the "lack of motivators or inadequate motivators for supporting the realization of the strategic objectives" (mean $=2.75)$. This confirms the thesis that the lack 
of an appropriate incentive system, which would link employee rewards with the level of completion of strategic objectives, is a major threat to the success of the strategy implementation process.

The "excessive number of strategic objectives included in the strategy" took fourth place among the factors that cause most problems in the strategy implementation process $($ mean $=2.67)$. It can therefore be concluded that small businesses make mistakes as early as at the stage of designing the strategy, because instead of selecting one or two strategic objectives and focusing on the activities aiming at their achievement, they divert their attention and scarce resources to the realization of too many strategic objectives. Such behavior may be caused by the lack of resolve among the management staff and the owners. They prefer to have several strategic objectives planned for realization rather than taking a difficult decision to abandon some of them since they are afraid of being accused of making a wrong choice, especially in a situation where they failed to achieve the selected objectives.

The problem associated with "lack of clear guidelines on the strategy implementation" took last place (mean $=2.55$ ). Perhaps the occurrence of this problem among the factors that cause most difficulties in the strategy implementation process in small companies may be caused by the fact that the entities of such a size often implement their first strategies and have not yet developed the methods for their implementation.

To sum up, it can be concluded that in the case of small companies one of the key factors hindering strategy implementation exists outside the organization (changing environment) and the organization has little or no control over it, while the second factor (financial resources) is also partly outside the organization as the amount of the financial resources available to a small company often depends on the decision of institutions such as banks that provide investment and development loans, and such institutions in Poland are reluctant to provide this type of support to small businesses.

The two tables below (Tables 5 and 6) contain the information about the most common problems and the problems that cause most difficulties during strategy implementation in large companies.

The analysis of the most common problems associated with strategy implementation in the group of large companies allows concluding that the list of these problems includes those faced by at least $28.4 \%$ of the companies ("occurrence of conflicting interest groups inside the organization which hinder the strategy implementation"), and those faced by just $35.8 \%$ of the companies ("attention of employees focused on operational activities 
irrespective of the realization of the strategic objectives" and "management staff overloaded with current problems which hinders the strategy implementation"). It can therefore be concluded that the remaining 24 problems occur less frequently in the large companies surveyed.

The list of the most common problems begins with "attention of employees focused on operational activities irrespective of the realization of the strategic objectives" $-35.8 \%$ of the responses. The next in order is "management staff overloaded with current problems which hinders the strategy implementation" - also $35.8 \%$ of the responses. Third place was the fact that "employees do not know how their daily work contributes to the strategy implementation" $-32.8 \%$ of the responses, worth considering whether these three problems are interrelated. If the management staff is so overloaded with current affairs that this hinders the strategy implementation, it should not surprise anyone that employees without a model to follow, such as the management staff showing by their actions that the strategy is most important, will focus their attention primarily on the performance of operational activities without a reflection on whether such activities are linked with the strategic objectives. Such an approach of the employees may be additionally intensified by the fact that they do not know how their daily workload contributes to the strategy implementation.

The fourth problem included in the list refers to financial matters. Almost every third entity among the large companies surveyed complained about the lack of adequate financial resources assigned for strategy implementation. It is a little surprising that in large companies, which after all can obtain external financial support in the form of investment and development loans more easily than small businesses, the problem of insufficient funds for the strategy implementation occurs so frequently. The reasons of this can be found, like in the case of small businesses, in the lack of the ability to estimate properly the costs associated with strategy implementation.

Last place on the list of the most common problems is taken by "occurrence of conflicting interest groups inside the organization which hinder the strategy implementation". Large enterprises very often have welldeveloped organizational structures, employ hundreds of people and have numerous branches and subsidiaries abroad, therefore various interest groups can easily form in such entities. They will surely include also those for whom the strategy being implemented is associated more with threats (e.g. loss of the current position within the entire company, loss of power, reduced funding level) than opportunities. Therefore it should not be surprising that the groups for which maintaining the status quo is important, 
will be far less interested in implementing the strategy than the groups that see in the strategy being implemented an opportunity to improve their position. Friction will occur place among these groups, which will inevitably cause difficulties in the strategy implementation process. It seems that the presence of conflicting interest groups in large companies is one of the major problems faced by the management staff. This also demonstrates how difficult it is to make everyone in the organization face in the same direction.

Knowing the list of the most common problems, the authors wanted to find out whether this list corresponded to the list of the problems that caused most trouble in the strategy implementation process. In order to determine the extent of the problem, there was used, like in the case of small businesses, a five-point scale, where "1" meant "not a problem at all", while "5" - "huge problem". Table 6 lists the five problems that cause most trouble in the strategy implementation process in small businesses. The list includes the problems indicated by at least $10 \%$ of the companies surveyed.

An analysis of the data included in Tables 5 and 6 allows concluding that none of the problem situations that occurred in the companies surveyed with the highest frequency was found among the situations that cause most trouble in the strategy implementation process. This means that the implementation problems that occur most frequently among the large companies surveyed are not the ones that cause most difficulties in the strategy implementation process.

Another finding concerns the fact that most problems associated with the implementation in the large companies surveyed are caused by "lack of motivators or inadequate motivators for supporting the realization of the strategic objectives" (mean = 3.31). This situation affects almost every fourth company surveyed. This confirms the thesis that the lack of an appropriate incentive system, which would link employee rewards with the level of completion of strategic objectives, is a major threat to the success of the strategy implementation process.

The second factor that causes the most problems with implementation is the "lack of leaders who would effectively motivate the employees to implement the strategy" (mean = 3.27). There is no doubt that the first problem and the second problem are interrelated. There may be a lack of such leaders in the companies surveyed, because they have no support in the form of a set of motivators that may encourage employees to achieve strategic objectives. Without appropriate support in the form of a properly designed incentive system, it will be difficult even for the best leaders to convince rankand-file employees to engage in the strategy implementation process. 
The third problem that causes the most difficulties in strategy implementation was "strategic objectives defined irrespective of a reliable analysis of the reality" (mean $=3.25$ ). It can therefore be assumed that some of the large companies surveyed are trying to achieve strategic objectives that do not have strong support in the form of a well-performed strategic analysis. Therefore it should not be surprising that problems occur in the process of achieving objectives which ignore the reality. However it may be surprising that in large companies there occur situations in which strategic objectives defined without performing an in-depth analysis of the reality are approved.

The next two problems on the list generate the same level of difficulties in the strategy implementation - mean $=3.0$. These problems are: "lack of an effective system for communicating the strategic objectives" and "rapidly changing environment that forces frequent modifications of the strategy being implemented". Undoubtedly a company which cannot effectively provide employees with the information on the strategic objectives adopted in the strategy must take into account the fact that problems will appear during the realization of these objectives. This is because, if the information on strategic objectives does not get to the employees effectively, it is difficult to hope that their actions will be correlated with those objectives. The fact that on the list of the problems generating difficulties in the strategy implementation there appeared "rapidly changing environment that forces frequent modifications of the strategy being implemented" may indicate that even the companies recognized today as effective in implementing the strategy face the challenge of the skillful adaptation to the changes occurring in the environment. Without this ability, today's big winners may become tomorrow's big losers. Examples of even such companies as Eastman Kodak and Nokia clearly show that incompetent adaptation to the changing environment ends in failure.

\section{CONCLUSION}

When comparing the research results for small businesses and large companies, the following similarities between them can be indicated:

a) in the case of both groups of enterprises the list of the most common problems encountered during the strategy implementation included:

- attention of employees focused on operational activities irrespective of the realization of the strategic objectives (this problem affects $35.8 \%$ of large companies and $22.1 \%$ of small businesses),

- management staff overloaded with current problems which hinders the strategy implementation (35.8\% of large companies, $23.5 \%$ of small businesses). 
Therefore it can be concluded that a company, irrespective of its size, when starting the strategy implementation, must take into account the above two problems that may disrupt the implementation process. The company should also make such a division of responsibilities early enough so that the management staff is relieved to a maximum extent from dealing with current affairs in order to focus on the activities associated with the effective implementation of the strategy. In addition, it is essential to translate the strategy into operational activities in such a way that the employees focused on the performance of operational tasks could see the links between their tasks and the strategic objectives adopted for implementation. Only then will it be possible to achieve a state in which the employees are aware that their daily work has an impact on the realization of the company's strategic objectives.

The differences include the following:

- in small businesses there predominate problems from the area "employee involvement" (3 of 5), while in large companies most problems (2 of 5) are from the area "other". Employees in small companies resist changes associated with the strategy being implemented, their involvement in the strategy implementation process decreases over time and they are focused on the performance of operational activities, whereas strategy implementation in large companies is disturbed by the friction between intra-organizational conflicting interest groups and the lack of adequate financial resources for implementing the strategy.

- in small businesses the area of "rapidly changing environment that forces frequent modifications of the strategy being implemented" was a key problem that stood out among other problems due to the frequency of responses $-36.8 \%$. In the case of large companies there is no a single implementation problem that would stand out among other problems, because the percentage difference between the first problem (35.8\%) and the fourth problem $(31.3 \%)$ on the list is 4.5 percentage points. Nevertheless, the problems that are encountered most often by large enterprises include "attention of employees focused on operational activities irrespective of the realization of the strategic objectives" $(35.8 \%)$ and "management staff overloaded with current problems which hinders strategy implementation" (35.8\%).

- large companies experience a negative impact of negligence in the area of "information flow" because they are affected by the problem of lack of knowledge among employees about the impact of their daily work on the strategy implementation process. It seems that this type of threat to the strategy implementation process is typical just for large companies since 
these are the entities that employ hundreds of people. In such large organizations it is a challenge for the management staff to create such an information flow system that will allow delivering an appropriate message to all employees.

These findings concerned the similarities and differences in the area of problems encountered most often by small and large companies in the strategy implementation process. The fact that they face these problems does not mean that these are the issues that cause most difficulties during the strategy implementation. An analysis of the responses given by representatives of small and large companies allows drawing the following conclusions:

- "Rapidly changing environment that forces frequent modifications of the strategy being implemented" was not only the problem that occurred most commonly (36.8\% of responses) among small companies, but was also the second largest problem that caused most difficulties in the strategy implementation process. The other four problems from the list of issues that cause most difficulties do not coincide with the most common problems.

- In the group of large companies, the list of the most common problems does not coincide at all with the list of issues that cause most difficulties in the strategy implementation process.

- For both small and large companies the list of issues that cause most difficulties during the strategy implementation process included:

- rapidly changing environment that forces frequent modifications of the strategy being implemented,

- lack of motivators, or inadequate motivators for supporting the realization of the strategic objectives.

Thus it can be concluded that regardless of the size of a company, the changes occurring in the environment can significantly hinder the strategy implementation process. In addition, this process will be disturbed by the lack of an appropriate incentive system that would support the achievement of strategic objectives.

- When analyzing the differences between small and large enterprises, it should be concluded that the following situations cause far more problems to large companies than to small businesses: lack of leaders who would effectively motivate the employees to implement the strategy; lack of an effective system for communicating the strategic objectives; and strategic objectives defined irrespective of a reliable analysis of the reality. It should be noted here that all these problems are intra-organizational factors and the company can have an active influence on each of them. 
- The following situations cause far more problems to small businesses than to large companies: insufficient financial resources allocated for the strategy implementation; excessive number of strategic objectives included in the strategy; and lack of clear guidelines on the strategy implementation. Thus in the case of small businesses it can be stated that they make mistakes as early as at the stage of designing the strategy (excessive number of strategic objectives, underestimation of the budget for strategy implementation, lack of guidelines on strategy implementation), while these mistakes manifest themselves negatively at the stage of the implementation of the strategy.

- It turned out that one of the key factors hindering strategy implementation primarily in small businesses but also in large companies was outside the organization (changing environment) and the organization has little or no control over it. Hence this raises the question of whether companies are trying somehow (e.g. by monitoring the environment) to mitigate the negative impact of this factor on the strategy implementation process.

To sum up, when answering the research question RQ1 (What factors most often hinder the implementation of the strategy in small and large companies?), it should be stated that the factors that most often hinder the implementation of strategy in successful small and large companies include: management staff overloaded with current problems which hinders strategy implementation and attention of employees focused on operational activities irrespective of the realization of the strategic objectives. This means that the issues associated with the current functioning of a company, regardless of its size, may burden the management staff and absorb the involvement of the employees to such an extent that maintaining the "strategic course" set by the company is at a serious risk.

When answering the research question RQ2 (What factors cause most difficulties in the implementation of strategy in small and large companies?), it should be stated that for both small and large successful companies most difficulties in the strategy implementation process are caused by rapidly changing environment that forces frequent modifications of the strategy being implemented and lack of motivators or inadequate motivators for supporting the realization of the strategic objectives. While the second factor (concerning an appropriate incentive system) is confirmed by the results of the research of other authors, the first factor (concerning the impact of the environment) is specific, because in the studies conducted by other authors referred to in this paper there is no mention about the impact of the environment on the strategy implementation process. Therefore it seems that future studies on the problems 
associated with the implementation of strategy in companies should put more emphasis on determining the impact of the environment on the strategy implementation process.

\section{REFERENCES}

Abraham, S., Blue Oceans, Temporary Monopolies, and Lessons from Practice, "Strategy \& Leadership", vol. 34, no. 5, pp. 52-57, 2006.

Abraham, S., Leavy, B., After 15 Editions: The Authors of Strategic Management Textbook Reflect, An Interview with A. A. Thompson, A. J. Strickland and J. E. Gamble, "Strategy \& Leadership", vol. 35, no. 4, pp. 38-42, 2007.

Alexander, L. D., Successfully Implementing Strategic Decisions, "Long Range Planning", vol. 18, issue 3, pp. 91-97, June 1985.

Al-Ghamdi, S. M., Obstacles to Successful Implementation of Strategic Decisions: The Saudi Case, Department of Management \& Marketing, College of Industrial Management, Dhahran, Kingdom of Saudi Arabia, 2005 (available at: http://www.google.pl/url?sa= $\mathrm{t} \& \mathrm{rct}=\mathrm{j} \& \mathrm{q}=$ obstacles $\% 20$ to $\% 20$ successful $\% 20$ implementation $\% 20 \mathrm{of} \% 20$ strategic $\% 20 \mathrm{de}$ cisions $\% 3 \mathrm{~A} \% 20 \&$ source $=$ web\&cd $=1 \&$ ved $=0 \mathrm{CCIQFjAA \& url}=\mathrm{http} \% 3 \mathrm{~A} \% 2 \mathrm{~F} \% 2 \mathrm{Ffaculty}$. kfupm.edu.sa\%2FMGM\%2Fsghamdi\%2Fupdate-1\%2Ffinalpaperobstacles.doc\&ei= q7kNT4WICI3FswaD_dCgBA\&usg=AFQjCNF_trkQXXXRfbZN9A-X32VVcXHag\& cad $=$ rja - accessed on $15 / 06 / 2015$ ).

Balanced Scorecard Statistics (available at: http://www.valuecreationgroup.com/balanced scorecard_statistics.htm - accessed on 20/05/2015).

Beer, M., Eisenstat, R. A., The Silent Killers of Strategy Implementation and Learning, "Sloan Management Review", vol. 41, no. 4, pp. 29-40, 2000.

Carciumaru, R., Candea, D., Strategy Implementation Tools in Big and Very Big Romanian Companies, "Review of Management \& Economic Engineering", vol. 11, no. 2, pp. 145-154, 2012.

Carlopio, J., Harvey, M., The Development of a Social Psychological Model of Strategy Implementation, "International Journal of Management", vol. 29, no. 3, part 1, pp. 75-85, September 2012.

Čatera, T., Pučko, D., Factors of Effective Strategy Implementation: Empirical Evidence from Slovenian Business Practice, "Journal for East European Management Studies", vol. 15, pp. 207-236, 2010.

Cocks, G., Emerging Concepts for Implementing Strategy, "The TQM Journal”, vol. 22, issue 3, pp. 260-266, 2010.

Gendron, M., Using the Balanced Scorecard, "Harvard Management Update: A Newsletter from Harvard Business School”, vol. 2, no. 10, pp. 7-10, 1997.

Hrebiniak, L. G., Making Strategy Work. Leading Effective Execution and Change. Pearson Education, Upper Saddle River, 2005.

Hussey, D. E., Implementing Corporate Strategy: Using Management Education and Training, "Long Range Planning", vol. 18, issue 5, pp. 28-37, October 1985. 
Hussey, D. E., Management Training a Key Tool for Strategy Implementation, "Strategic Change", vol. 5, pp. 263-274, 1996.

Hutzschenreuter, T., Kleindienst, I., Strategy-Process Research: What Have We Learned and What Is Still to Be Explored, "Journal of Management”, 32 (5), pp. 673-720, 2006.

Isherwood, A., Strategy Tool Usage. What Tools Do Practicing Managers Use?, ai:consortia, pp. 1-25, 7 June 2011 (available at: http://www.aiconsortia.com/documents/strategy-toolusage-survey.pdf. - accessed on 12/04/2015).

Jones, P., Komunikowanie strategii [Communicating the Strategy]. Oficyna a Wolters Kluwer business, Warsaw, 2010.

Kaplan, R. S., Risk Management and the Strategy Execution System, "Balanced Scorecard Report. Harvard Business Publishing”, pp. 1-8, November-December 2009 (available at: http://www.exed.hbs.edu/assets/Documents/risk-management-strategy.pdf - accessed on 10/05/2015).

Kaplan, R. S., Norton, D. P., Creating the Office of Strategic Management, 2005a, (available at: http://www.hbs.edu/faculty/Publication\%20Files/05-071.pdf - accessed on 15/04/2015).

Kaplan, R. S., Norton, D. P., The Office of Strategy Management, "Harvard Business Review" vol. 83, issue 10, pp. 72-80; 2005 b.

Markiewicz, P., Methodical Aspects of Applying Strategy Map in an Organization, "Business, Management and Education", 11 (1), pp. 153-167, 2013.

Mason, A., Management Training and Development in Medium-Sized UK Business Organisations. Harbridge Consulting Group Ltd, London, 1993.

Miller, S., Implementing Strategic Decisions: Four Key Factors, "Organisation Studies”, vol. 18 (4), pp. 577-602, 1997.

Neilson, G. L., Martin, K. L, Powers, E., The Secrets to Successful Strategy Execution, "Harvard Business Review", 1, pp. 61-70, 2008.

Pugh, J., Bourgeois III, L. J., Doing Strategy, “Journal of Strategic Management”, vol. 4, no. 2, pp. 172-179, 2011.

Salih, A., Doll, Y., A Middle Management Perspective on Strategy Implementation, "International Journal of Business and Management”, vol. 8, no. 22, pp. 32-39, 2013.

Saunders, M., Mann, R. Smith, R., Implementing Strategic Initiatives: A Framework of Leading Practices, "International Journal of Operations \& Production Management", vol. 28, issue 11, pp. 1095-1123, 2008.

Speculand, R., The Great Big Strategy Challenge, "Strategic Direction", vol. 22, issue 3, pp. 3-5, 2006.

Three Reasons Why Good Strategies Fail: Execution, Execution... (available at: (http://knowledge. wharton.upenn.edu/article/three-reasons-why-good-strategies-fail-execution-execution/ _ accessed on 22/05/2015).

Tovey, L., Management Training and Development in Large UK Business Organisations. Harbridge Consulting Group Ltd., London, 1991.

Wołczek, P., Wdrażanie strategii jednym z najstabszych ogniw zarzadzania strategicznego [Implementation of Strategy as One of the Weakest Link of Strategic Management] "Studia i Prace Kolegium Zarządzania i Finansów", no. 116, pp. 205-216, 2012.

Received: August 2015, revised: May 2017 


\section{APPENDIX}

Table 1

Traits of an organization affecting the effectiveness of the strategy implementation process

\begin{tabular}{l|c|c|c}
\hline \multicolumn{1}{c|}{ Traits of organization } & $\begin{array}{c}\text { Strength } \\
\text { Index } \\
\text { (max. 100) }\end{array}$ & $\begin{array}{c}\text { SSI } \\
\text { companies }\end{array}$ & $\begin{array}{c}\text { WSI } \\
\text { companies }\end{array}$ \\
\hline $\begin{array}{l}\text { Everyone has a good idea of the decisions and actions for } \\
\text { which he or she is responsible - DMP }\end{array}$ & 81 & $71 \%$ & $32 \%$ \\
\hline $\begin{array}{l}\text { Important information about the competitive environment } \\
\text { gets to headquarters quickly - I }\end{array}$ & 68 & $77 \%$ & $45 \%$ \\
\hline Once made, decisions are rarely second-guessed - DMP & 58 & $55 \%$ & $29 \%$ \\
\hline $\begin{array}{l}\text { Information flows freely across organizational boundaries } \\
- \text { I }\end{array}$ & 58 & $55 \%$ & $21 \%$ \\
\hline $\begin{array}{l}\text { Field and line employees usually have the information they } \\
\text { need to understand the bottom-line impact of their day-to- } \\
\text { day choices - I }\end{array}$ & 55 & $61 \%$ & $28 \%$ \\
\hline
\end{tabular}

DMP - decision-making powers, I - information, SSI - strong in the strategy implementation, WSI - weak in the strategy implementation

Source: own study based on: Neilson, Martin and Powers (2008).

Table 2

The factors that may hinder strategy implementation

\begin{tabular}{|c|}
\hline AREAS \\
\hline CONTENT OF THE STRATEGY \\
\hline aguely formulated assumptions to the strategy (SC) \\
\hline $\begin{array}{l}\text { nternal inconsistency of the strategy implemented (inconsistency in the vision, goals, } \\
\text { chedule, budget) (SC) }\end{array}$ \\
\hline Inflexibility of the strategy (single variants of the solutions adopted in the strategy) (SC) \\
\hline An excessive number of strategic objectives included in the strategy (SC) \\
\hline Strategic objectives defined irrespective of a reliable analysis of the reality (SC) \\
\hline ORGANIZATIONAL STRUCTURE, PROCEDURES AND GUIDELINES \\
\hline Lack of clear guidelines on the strategy implementation (SPG) \\
\hline The organizational structure not matched to the strategy being implemented (SPG) \\
\hline $\begin{array}{l}\text { No methods of proceeding in situations critical for the strategy implementation have } \\
\text { been worked out (SPG) }\end{array}$ \\
\hline INFORMATION FLOW \\
\hline Lack of an effective system for communicating the strategic objectives (IF) \\
\hline Poor or insufficient exchange of information regarding the strategy implementation (I) \\
\hline Employees do not know how their daily work contributes to the strategy implementation (IF) \\
\hline $\begin{array}{l}\text { The strategy has not been presented to employees, which causes that they do not know } \\
\text { ts assumptions (IF) }\end{array}$ \\
\hline $\begin{array}{l}\text { o much information and data, which slows down the process of making key } \\
\text { cisions implementation (IF) }\end{array}$ \\
\hline
\end{tabular}


Table 2, cont.

\section{AREAS \\ LEADERSHIP}

Senior management does not take actions supporting the strategy implementation (L)

The management has no experience in implementing the strategy (L)

Senior managers lack the knowledge required for the implementation of the strategy (L)

Management staff overloaded with current problems which hinders the strategy

implementation (I)

The employees essential in terms of the strategy implementation do not identify themselves with this strategy $(\mathrm{L})$

Lack of leaders who would effectively motivate the employees to implement the strategy (L)

Lack of persons responsible for the strategy implementation (L)

\section{EMPLOYEE INVOLVEMENT}

Lower-level employees do not accept the strategy (EI)

The resistance of employees to changes associated with the strategy implementation (EI)

Employees are reluctant to share important information or knowledge concerning the strategy implementation (EI)

The involvement of employees in the strategy implementation process keeps decreasing over time (EI)

Attention of employees focused on operational activities irrespective of the realization of the strategic objectives (EI)

\section{OTHER}

Insufficient financial resources allocated for the strategy implementation (O)

Rapidly changing environment that forces frequent modifications of the strategy being implemented (O)

Lack of motivators or inadequate motivators for supporting the realization of the strategic objectives $(\mathrm{O})$

Occurrence of conflicting interest groups inside the organization which hinder the strategy implementation $(\mathrm{O})$

Source: own study.

Table 3

Most common problems occurring during strategy implementation — small companies

\begin{tabular}{l|c|c}
\hline \multicolumn{1}{c|}{ Problem } & $N$ & $\%$ \\
\hline $\begin{array}{l}\text { Rapidly changing environment that forces frequent modifications of the strategy } \\
\text { being implemented (O) }\end{array}$ & 25 & $36.8 \%$ \\
\hline $\begin{array}{l}\text { Management staff overloaded with current problems which hinders the strategy } \\
\text { implementation (I) }\end{array}$ & 16 & $23.5 \%$ \\
\hline $\begin{array}{l}\text { Attention of employees focused on operational activities irrespective of the } \\
\text { realization of the strategic objectives (EI) }\end{array}$ & 15 & $22.1 \%$ \\
\hline $\begin{array}{l}\text { The involvement of employees in the strategy implementation process keeps } \\
\text { decreasing over time (EI) }\end{array}$ & 15 & $22.1 \%$ \\
\hline $\begin{array}{l}\text { The resistance of employees to changes associated with the strategy } \\
\text { implementation (EI) }\end{array}$ & 13 & $19.1 \%$ \\
\hline
\end{tabular}

Source: own study based on the results of the research. 
Table 4

Problems that cause most difficulties during strategy implementation - small companies

\begin{tabular}{l|c|c|c}
\hline \multicolumn{1}{c|}{ Problem } & $N$ & $\%$ & Mean \\
\hline $\begin{array}{l}\text { Insufficient financial resources allocated for the strategy } \\
\text { implementation (O) }\end{array}$ & 11 & $16.2 \%$ & 3.82 \\
\hline $\begin{array}{l}\text { Rapidly changing environment that forces frequent modifications of } \\
\text { the strategy being implemented (O) }\end{array}$ & 25 & $36.8 \%$ & 3.00 \\
\hline $\begin{array}{l}\text { Lack of motivators or inadequate motivators for supporting the } \\
\text { realization of the strategic objectives (O) }\end{array}$ & 9 & $13.2 \%$ & 2.75 \\
\hline $\begin{array}{l}\text { An excessive number of strategic objectives included in the strategy } \\
(\mathrm{S})\end{array}$ & 9 & $13.2 \%$ & 2.67 \\
\hline Lack of clear guidelines on the strategy implementation (SPG) & 11 & $16.2 \%$ & 2.55 \\
\hline
\end{tabular}

Source: own study based on the results of the research.

Table 5

Most common problems occurring during strategy implementation — large companies

\begin{tabular}{l|c|c}
\hline \multicolumn{1}{c|}{ Problem } & $N$ & $\%$ \\
\hline $\begin{array}{l}\text { Attention of employees focused on operational activities irrespective of the } \\
\text { realization of the strategic objectives (EI) }\end{array}$ & 24 & $35.8 \%$ \\
\hline $\begin{array}{l}\text { Management staff overloaded with current problems which hinders the } \\
\text { strategy implementation (I) }\end{array}$ & 24 & $35.8 \%$ \\
\hline $\begin{array}{l}\text { Employees do not know how their daily work contributes to the strategy } \\
\text { implementation (IF) }\end{array}$ & 22 & $32.8 \%$ \\
\hline $\begin{array}{l}\text { Insufficient financial resources allocated for the strategy implementation (O) } \\
\text { Occurrence of conflicting interest groups inside the organization which hinder } \\
\text { the strategy implementation (O) }\end{array}$ & 21 & $31.3 \%$ \\
\hline
\end{tabular}

Source: own study based on the results of the research.

Table 6

Problems that cause most difficulties during strategy implementation - large companies

\begin{tabular}{l|c|c|c}
\hline \multicolumn{1}{c|}{ Problem } & $N$ & $\%$ & Mean \\
\hline $\begin{array}{l}\text { Lack of motivators or inadequate motivators for supporting the } \\
\text { realization of the strategic objectives (O) }\end{array}$ & 16 & $23.9 \%$ & 3.31 \\
\hline $\begin{array}{l}\text { Lack of leaders who would effectively motivate the employees to } \\
\text { implement the strategy (L) }\end{array}$ & 11 & $16.4 \%$ & 3.27 \\
\hline $\begin{array}{l}\text { Strategic objectives defined irrespective of a reliable analysis of the } \\
\text { reality }\end{array}$ & 8 & $11.9 \%$ & 3.25 \\
\hline $\begin{array}{l}\text { Lack of an effective system for communicating the strategic objectives } \\
\text { (IF) }\end{array}$ & 12 & $17.9 \%$ & 3.00 \\
\hline $\begin{array}{l}\text { Rapidly changing environment that forces frequent modifications of } \\
\text { the strategy being implemented (O) }\end{array}$ & 18 & $26.9 \%$ & 3.00 \\
\hline
\end{tabular}

Source: own study based on the results of the research. 


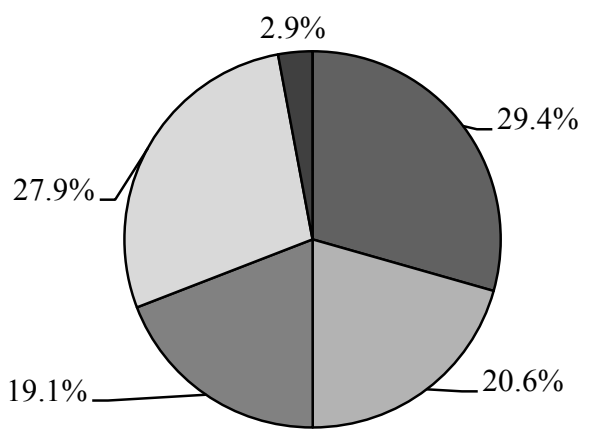

$\square$ strategy existing only "in the mind of the boss"

$\square$ strategy in the form of verbal arrangements known only to the top management

$\square$ strategy in the form of verbal arrangements known to every employee

$\square$ formalized strategy in the form of a document known to the management

$\square$ formalized strategy in the form of a document known to every employee

Figure 1. Form of the strategy - small companies

Source: own study based on the results of the research.

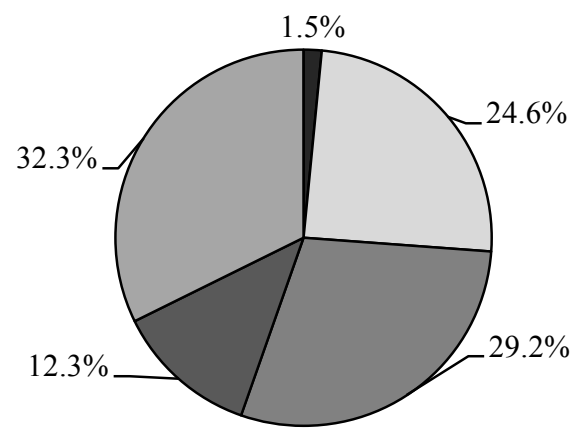

口strategy existing only "in the mind of the boss"

$\square$ strategy in the form of verbal arrangements known only to the top management

$\square$ strategy in the form of verbal arrangements known to every employee

$\square$ formalized strategy in the form of a document known to the management

$\square$ formalized strategy in the form of a document known to every employee

Figure 2. Form of the strategy - large companies

Source: own study based on the results of the research. 


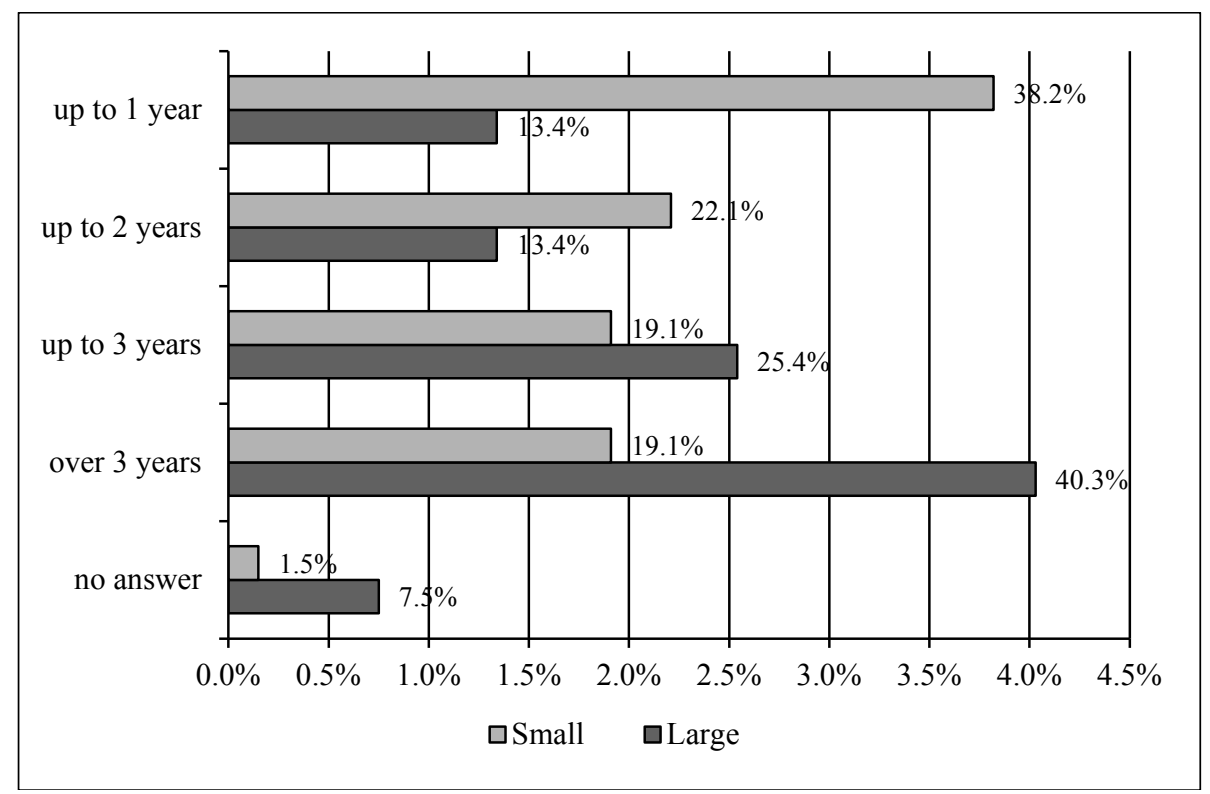

Figure 1. The period for which the strategy looks ahead

Source: own study based on the results of the research.

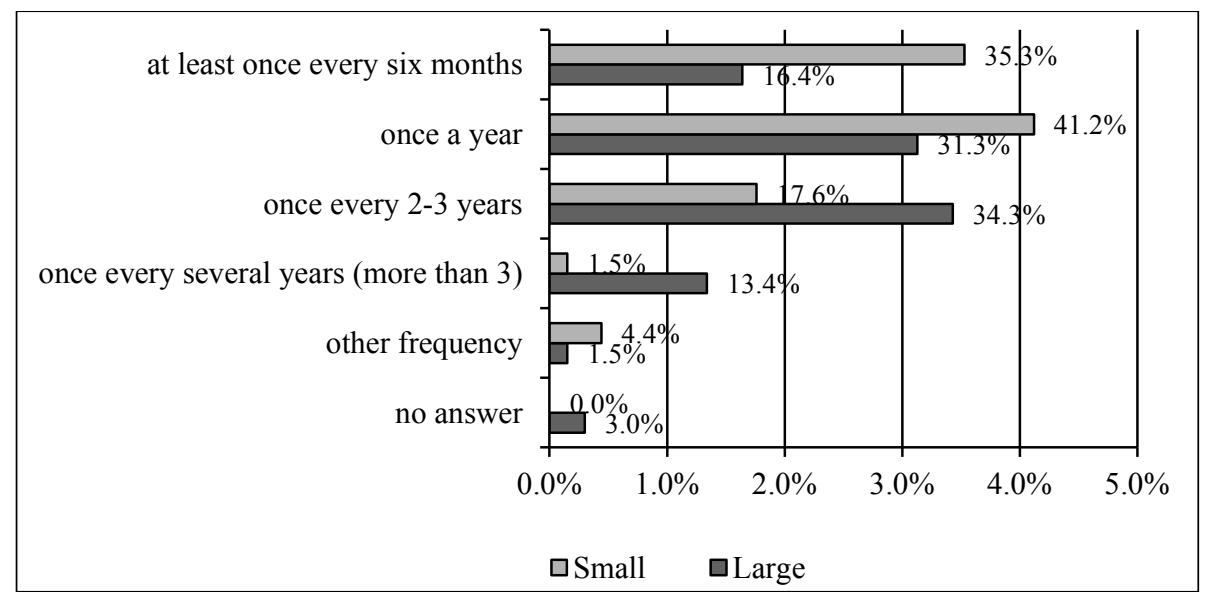

Figure 2. The frequency of updates to the strategy

Source: own study based on the results of the research. 